\title{
Sympathetic reinnervation and heart rate variability after cardiac transplantation
}

\author{
S W Lord, R H Clayton, L Mitchell, J H Dark, A Murray, J M McComb
}

\begin{abstract}
Background-Heart rate variability is thought to measure autonomic modulation, but the relation has never been demonstrated directly in humans.

Aim-To test the hypothesis that increased low frequency heart rate variability reflects sympathetic reinnervation after cardiac transplantation.

Patients-24 cardiac transplant recipients at the time of routine surveillance coronary angiography two or more years after cardiac transplantation, and 10 controls with normal coronary arteries undergoing angiography for investigation of chest pain.
\end{abstract}

Setting-Regional cardiothoracic centre. Methods-Sympathetic effector function at the sinus node was assessed by measuring the fall in cycle length for two minutes after injection of tyramine to the artery supplying the sinus node. Heart rate variability was measured from three-minute RR interval sequences at rest, during metronomic respiration, and before and after atropine.

Results-The logarithm of the low frequency component of heart rate variability during metronomic respiration was linearly related to the logarithm of the change in cycle length after injection of tyramine $\left(\mathbf{R}^{2}=0.28, P=0.007\right)$. Absolute units more accurately reflected sympathetic effector function than did normalised units or the ratio of low frequency to high frequency. Atropine did not affect high frequency heart rate variability in transplant recipients.

Conclusions-The low frequency component of heart rate variability is directly related to sympathetic reinnervation to the sinus node.

(Heart 1997;77:532-538)

Keywords: heart rate variability; reinnervation; sympathetic nervous system; cardiac transplantation

Heart rate variability is mediated by cardiac nerves, and has been used as a measure of "autonomic tone". The precise relation between heart rate variability and autonomic innervation has not been measured directly, but has been inferred from the fact that heart rate variability is reduced immediately after transplantation when all extracardiac nerves to the sinus node are divided, and because it may be abolished using pharmacological autonomic blockade. ${ }^{1-4}$

The spectrum obtained from frequency analysis of sequences of $R R$ intervals may be divided into two parts, a low frequency (LF) component and a high frequency (HF) component. The LF component is thought to be related to both sympathetic and parasympathetic innervation, and the $\mathrm{HF}$ component to parasympathetic innervation alone on the basis of experiments involving specific intravenous autonomic blocking agents..$^{1-3}$

Heart rate variability increases with time after transplantation, suggesting that reinnervation occurs. ${ }^{56} \quad \mathrm{We}^{7}$ and others ${ }^{89}$ have observed sympathetic reinnervation after cardiac transplantation using intracoronary injection of tyramine, which causes release of noradrenaline only from intact presynaptic sympathetic nerve terminals, and so causes a change in heart rate only if reinnervation has taken place. In contrast to previous demonstrations of sympathetic reinnervation $\mathrm{we}^{10}$ and others ${ }^{411}$ have not been able to demonstrate parasympathetic reinnervation. Assuming that parasympathetic reinnervation does not occur, and that we can quantitate sympathetic reinnervation using tyramine, the cardiac transplant recipient is therefore a new model of denervation and partial sympathetic reinnervation with which to investigate the specific contribution of cardiac nerves to autonomic function.

The aim of this study was to examine the relation between sympathetic and parasympathetic innervation of the heart, and the various components of heart rate variability using the cardiac transplant recipient as a model. We hypothesised that LF but not HF measures of heart rate variability would be related to response to tyramine among transplant recipients, and that atropine would have no effect on heart rate variability in transplant recipients.

\section{Methods}

SUBJECTS

Twenty four cardiac transplant recipients were studied at the time of routine surveillance coronary angiography two or more years after transplantation. All were in sinus rhythm and none had overt sinus node dysfunction. Donor and recipient age and time after transplantation were recorded. Calcium channel blocking agents and nitrates were discontinued at least 36 hours before all studies. None was taking $\beta$ blockers. Immunosuppression including 
cyclosporin, azathioprine, and prednisolone was continued throughout. Subjects with permanent pacemakers, diabetes or significant renal impairment were excluded.

Ten control subjects were recruited from a population awaiting coronary angiography for assessment of chest pain. Subjects were selected prospectively if they had a low prior probability of coronary artery disease on clinical grounds. $\beta$ blockade, calcium channel blockade, and nitrates were discontinued at least 36 hours before the angiogram and before al studies. Potential control subjects were excluded at the time of angiography if there was any impairment of ventricular function, any valve lesions or any significant coronary artery lesions (stenosis $>50 \%$ ).

Approval was obtained from the Joint Ethical Committee of the University of Newcastle upon Tyne and Newcastle Health Authority, and prior informed consent was obtained from all subjects.

INTRACORONARY TYRAMINE

After routine coronary angiography, either for surveillance (transplant recipients) or investigation of chest pain (control subjects), tyramine was injected into each coronary artery following the protocol of Wilson et al. ${ }^{8}$ Tyramine $(8 \mu \mathrm{g} / \mathrm{kg})$ was injected into the left coronary artery and then $(4 \mu \mathrm{g} / \mathrm{kg})$ into the right; the catheter was immediately flushed with heparinised saline after each injection. Surface ECGs were recorded from a chest lead at a paper speed of $100 \mathrm{~mm} / \mathrm{s}$ for 10 beats before and at least two minutes after tyramine injection. Coronary angiograms were then reviewed to identify the sinus node artery, and consecutive $R R$ intervals were measured manually in milliseconds from the record of that injection using a digitising tablet (Calcomp 2000, Anaheim, California, USA) linked to a personal computer via the serial port.

Resting cycle length was averaged over 10 beats before injection. The minimum cycle length averaged over three consecutive sinus beats was determined from the $R R$ interval series, and was confirmed by inspection of the ECG and the tachogram. Responses to tyramine were calculated as the natural logarithm of the difference between the resting and minimum cycle lengths, and expressed as changes in heart rate after injection of tyramine to allow comparison with Wilson's original data.

\section{HEART RATE VARIABILITY}

Transplant recipients were studied supine six hours after angiography. Control subjects were studied supine six hours after angiography and again at between six and 17 months following angiography. Two three-minute ECG recordings were made from a chest lead. During the second recording, the subject was instructed to breathe in time with a signal from the investigator at a rate of 10 breaths per minute $(0 \cdot 167 \mathrm{~Hz})$. All RR intervals from each recording were then measured manually in milliseconds using a digitising tablet as above. Any ectopic beats were identified and the short coupling interval and compensatory pause replaced by an interval length equal to the mean of the two preceding $R R$ intervals. No recording had more than seven ectopic beats. The first 150 seconds of each $R R$ interval series were then resampled at $4 \mathrm{~Hz}$ using the method of Berger et $a l^{12}$ and any linear trend was removed. A series of five overlapping segments each 200 points (50 seconds) long and overlapping the previous segment by $50 \%$ were then obtained from each series. Each segment was zero padded to 256 points, multiplied by the Hanning function, and Fourier transformed. The resulting five spectra were then averaged to form a final estimate of the proportion of the variability in the signal at each frequency. LF and HF content were defined as the areas under the spectrum between 0.05 and $0.15 \mathrm{~Hz}$ and between 0.15 and $0.35 \mathrm{~Hz}$, respectively. The area was also calculated in normalised units. ${ }^{13}$ Sympathovagal balance was calculated as the ratio LF:HF. ${ }^{13}$

\section{ATROPINE STUDY}

After preliminary analysis of the results, it was decided to assess the contribution of parasympathetic innervation to heart rate variability. Heart rate variability was assessed after parasympathetic blockade in the 10 control subjects who were restudied both before and after atropine, and the final nine transplant recipients. Three-minute $R R$ interval traces were recorded at rest and during metronomic respiration both before and after intravenous injection of $1.8 \mathrm{mg}$ atropine.

\section{STATISTICAL ANALYSIS}

The distribution of the heart rate variability data was found to be skewed, therefore, all values were logarithmically transformed to approximate a normal distribution. Similarly, response to tyramine was expressed as the logarithm of the absolute change in cycle length after intracoronary injection. Values were compared between groups using Student's $t$ test, and between resting and metronomic respiration, and before and after atropine in the same subjects using paired $t$ testing. Relations between response to tyramine and heart rate variability were analysed using linear regression. Significance was set at $P<0.05$.

\section{Results}

SUBJECTS

Donor and recipient age, and time after transplantation are presented in table 1 .

\section{RESPONSE TO INTRACORONARY TYRAMINE}

Heart rate increased after intracoronary tyramine by a median of 18 (range 1 to 63) beats per minute in transplant recipients, and by a median of 30 (range 15 to 67) beats per minute in controls. Heart rate rose by more than five beats per minute in 21 of 24 cardiac transplant recipients and in all control subjects, meeting Wilson's definition of reinnervation. $^{8}$ Example patterns of response to tyramine are shown in figure 1 for a control 
Table 1 Characteristics of experimental subjects

\begin{tabular}{llclll}
\hline & Number & Male & $\begin{array}{l}\text { Age } \\
\text { (years) }\end{array}$ & $\begin{array}{l}\text { Donor } \\
\text { age } \\
\text { (years) }\end{array}$ & $\begin{array}{l}\text { Time after } \\
\text { transplant } \\
\text { (months) }\end{array}$ \\
\hline $\begin{array}{l}\text { Transplant recipients } \\
\text { Controls }\end{array}$ & 24 & 20 & $\begin{array}{l}47 \cdot 5(14 \cdot 7) \\
47.5(5 \cdot 8)\end{array}$ & $39 \cdot 0(8 \cdot 1)$ & $56 \cdot 6(31 \cdot 0)$ \\
\hline
\end{tabular}

All values are mean $(\mathrm{SD})$.

Table 2 Natural logarithm of low and high frequency content of the spectrum in transplant recipients and controls

\begin{tabular}{|c|c|c|c|c|}
\hline & \multicolumn{2}{|l|}{ High frequency } & \multicolumn{2}{|l|}{ Low frequency } \\
\hline & $\begin{array}{l}\text { Transplant } \\
\text { recipients } \\
(n=24)\end{array}$ & $\begin{array}{l}\text { Controls } \\
(n=10)\end{array}$ & $\begin{array}{l}\text { Transplant } \\
\text { recipients } \\
(n=24)\end{array}$ & $\begin{array}{l}\text { Controls } \\
(n=10)\end{array}$ \\
\hline $\begin{array}{l}\text { Rest } \\
\text { Metronomic respiration }\end{array}$ & $\begin{array}{l}0.21(0.83)^{\star} \dagger \\
0.95(1.27)^{\star}\end{array}$ & $\begin{array}{l}3.34(0.72) \dagger \\
4.89(1.38)\end{array}$ & $\begin{array}{l}-0.41(1.00)^{\star} \\
-0.58(1.19)^{\star}\end{array}$ & $\begin{array}{l}4 \cdot 14(0 \cdot 75) \\
3 \cdot 72(0.99)\end{array}$ \\
\hline
\end{tabular}

Values are expressed as mean (SD).

* Significant difference between transplant recipients and controls, $\mathrm{P}<0.01$; tbetween subjects at rest and during metronomic respiration, $\mathrm{P}<0.05$

Figure 1 Comparison of results from a control subject (upper panel), a transplant recipient in whom there was no evidence of reinnervation (middle panel), and a transplant recipient in whom there is evidence of sympathetic reinnervation (lower panel). The cardiac cycle length response to intracoronary injection of tyramine is shown on the left, and the spectrum from a resting $R R$ interval sequence on the right.
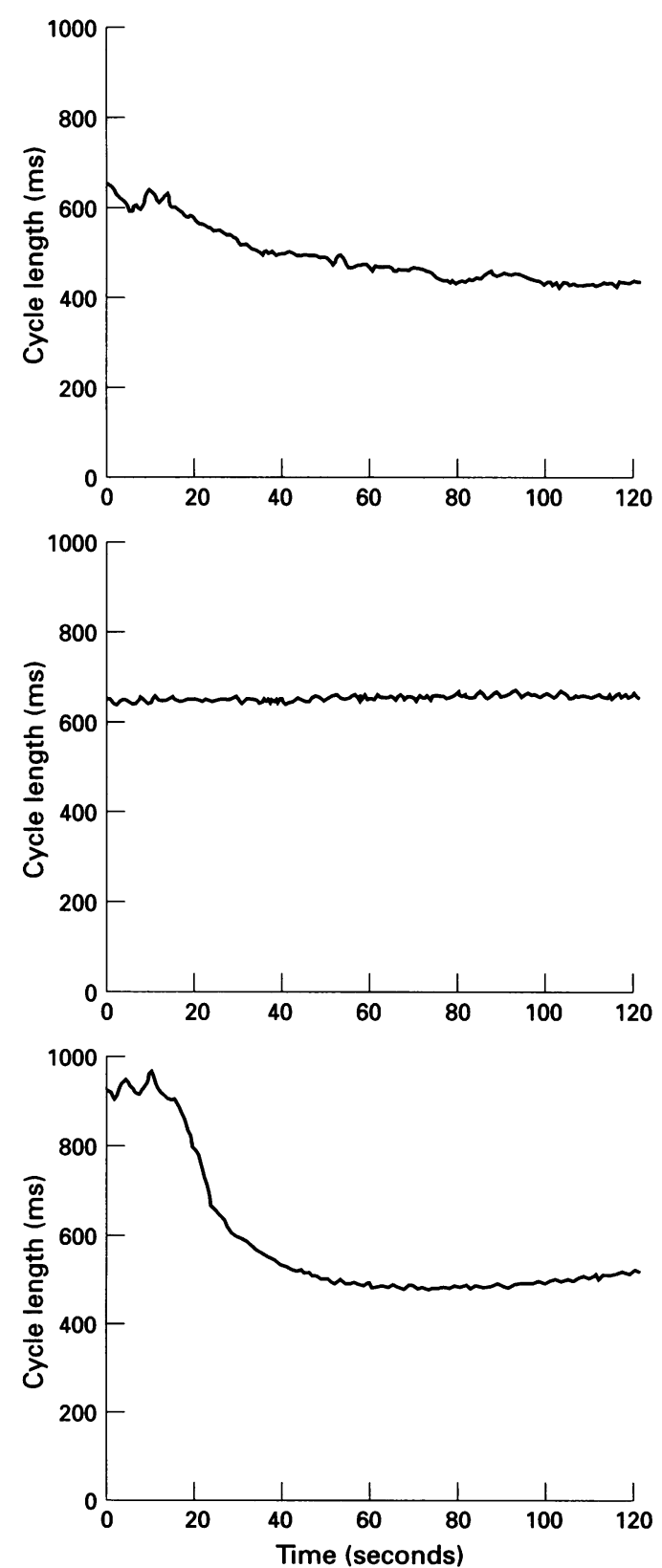

subject, a transplant recipient with no evidence of reinnervation, and a transplant recipient with evidence of reinnervation.

\section{HEART RATE VARIABILITY}

Figure 1 also shows examples of spectra derived from the resting $R R$ interval sequences in the same subjects. Although there is a dramatic response to tyramine in the transplant recipient with evidence of reinnervation, this is reflected only in an attenuated LF peak, and the continuing absence of an HF peak. Table 2 presents data from subjects studied at rest and during metronomic respiration. Both LF and HF components of the spectrum were significantly lower in transplant recipients compared with controls both at rest and during metronomic respiration. Results are shown only for absolute values of the LF and HF content of the spectrum, as values expressed as normalised units or as LF:HF ratio did not relate to response to tyramine either among transplant recipients or controls. Among control subjects the variability
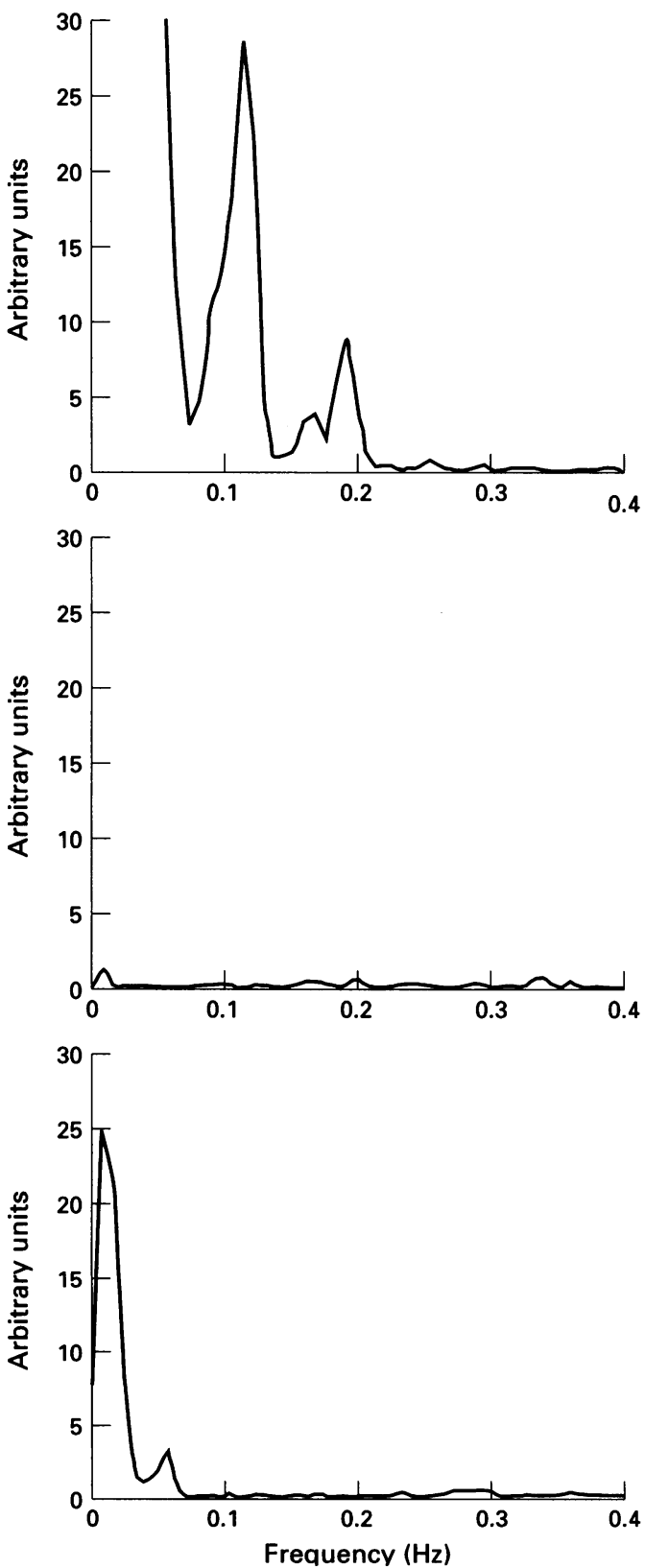

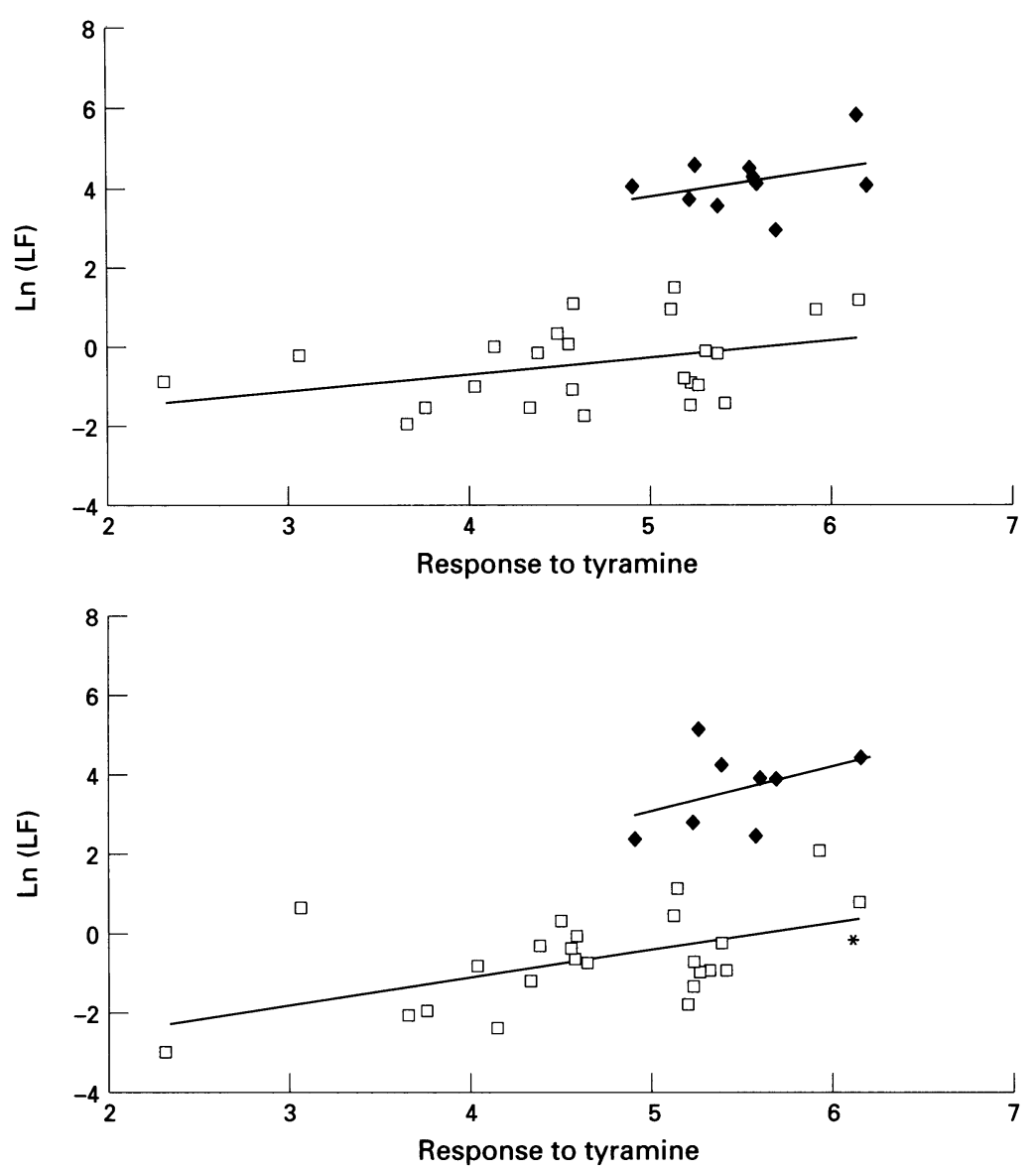

Figure 2 Relation between response to tyramine and the low frequency (LF) content of the spectrum recorded at rest (upper panel) and during metronomic respiration (lower panel). Data from transplant recipients are shown as open squares and from control subjects as diamonds. ${ }^{\star}$ Correlations statistically significant $(P<0.05)$.
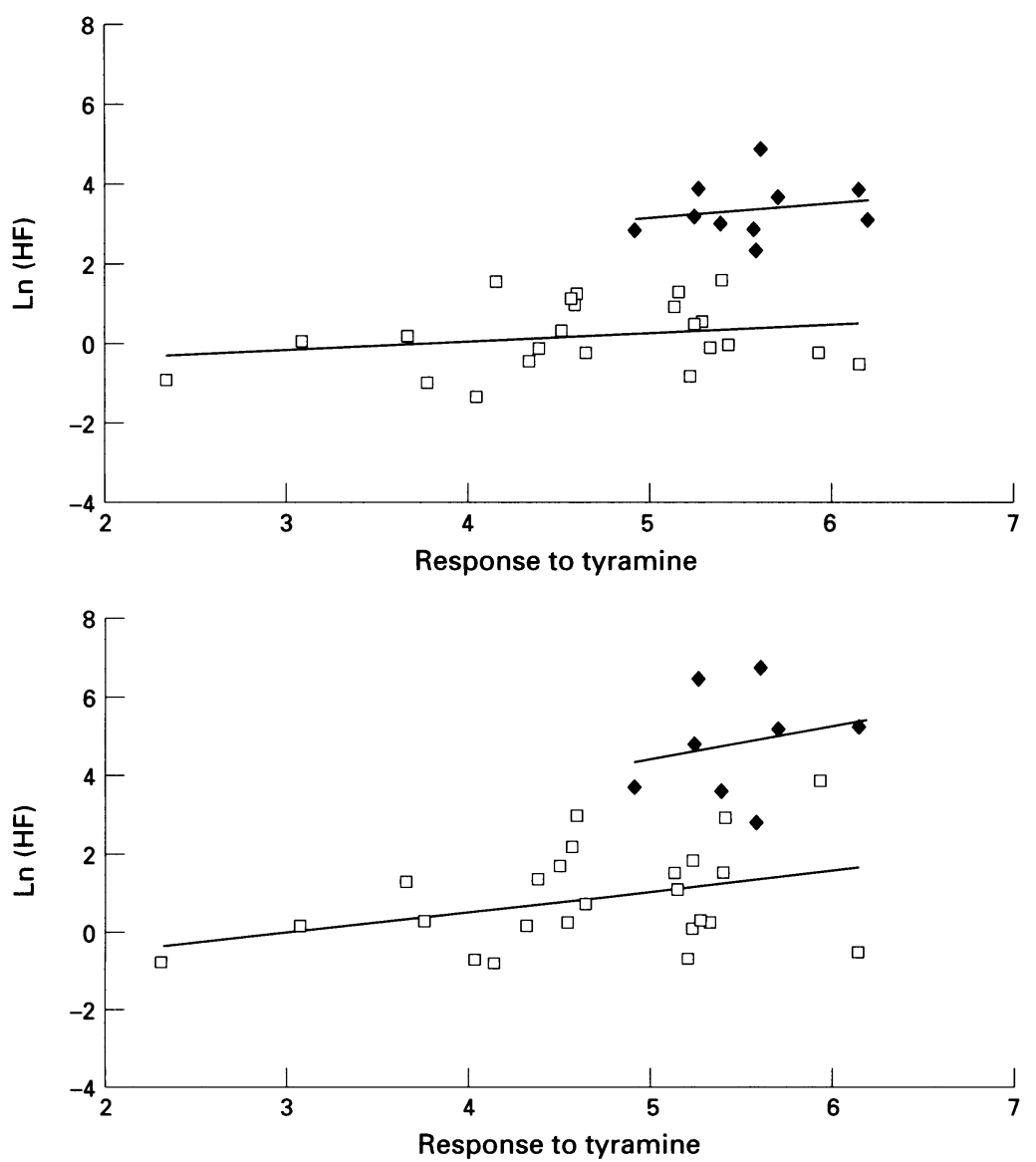

Figure 3 Relation between response to tyramine and the high frequency (HF) content of the spectrum recorded at rest (upper panel) and during metronomic respiration (lower panel). Data from transplant recipients are shown as open squares and from control subjects as diamonds. of the measurements of heart rate variability was assessed by comparing the difference of each pair of values to its mean. For LF content of the spectrum the mean difference was -0.39 units (range -1.63 to 1.87 ) and for HF content of the spectrum the mean difference was -0.33 units (range $-2 \cdot 12$ to $1 \cdot 33$ ).

\section{RELATION OF HEART RATE VARIABILITY TO RESPONSE TO TYRAMINE \\ Low frequency}

Among transplant recipients there was a significant relation between the LF component of the spectrum and response to tyramine only during metronomic respiration $\left(\mathrm{R}^{2}=0.28, \quad \mathrm{P}=\right.$ $0 \cdot 007$ ) (fig 2).

\section{High frequency}

The relation between HF content and response to tyramine was not significant in transplant recipients, unlike that between LF content and response to tyramine (fig 3 ).

\section{EFFECT OF ATROPINE}

Figures 4 and 5 show the relations between response to tyramine and the LF and HF components of heart rate variability before and after injection of atropine in control subjects. Regression lines from the first experiment (figures 2 and 3) are shown as dashed lines for comparison. Table 3 contains data from the nine transplant recipients and 10 control subjects studied before and after administration of atropine. Post-atropine values for transplant recipients were comparable with values from control subjects for both $\mathrm{HF}$ and LF components. Neither part of the spectrum was affected by atropine in the nine transplant recipients to whom it was given.

\section{Discussion}

This study has shown that heart rate variability is directly related to sympathetic reinnervation to the sinus node, confirming the inference of Bernardi and colleagues, ${ }^{14}$ and the assumptions of others..$^{515}$ It has also suggested that sympathetic effector function contributes to HF variation, previously thought to be related to parasympathetic innervation alone.

\section{HEART RATE VARIABILITY IN NORMAL}

\section{SUBJECTS}

Variations in heart rate are thought to be caused by cardiac nerves because pharmacological and surgical autonomic blockade abolish them. ${ }^{14}$ These variations may be analysed in more detail using frequency analysis to extract the proportion of the variability in the signal that can be explained by oscillations at each of the measured frequencies. A number of investigators has shown that typical spectra obtained from normal subjects contain peaks in an LF and an HF region. ${ }^{12}$ The HF peak has been related to parasympathetic nerves because it is abolished by atropine. The LF peak is affected by both atropine and sympathetic blockade, and its relation to the $\mathrm{HF}$ peak is possibly related to the sensitivity of the mechanism by which changes in blood pressure affect heart 

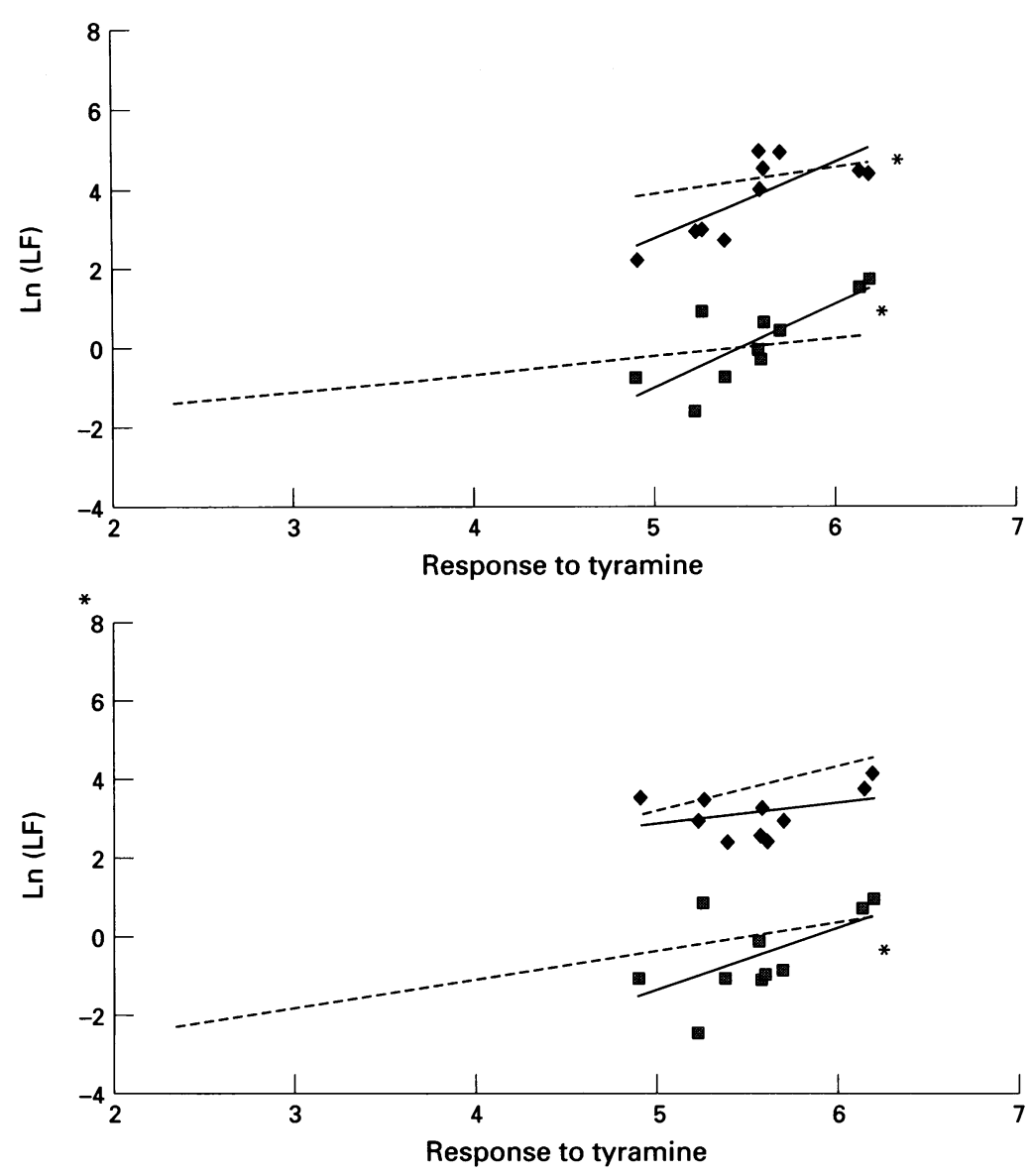

Figure 4 Relation between response to tyramine and the low frequency (LF) content of the spectrum in control subjects recorded at rest (upper panel) and during metronomic respiration (lower panel). Data from transplant recipients after atropine are not presented. Data from control subjects before atropine are shown as diamonds, and from control subjects after atropine as closed squares. Relations from the first experiment are reproduced as dashed lines for comparison. ${ }^{\star}$ Correlations statistically significant $(P<0 \cdot 05)$.

rate, the baroreflex. ${ }^{16}$ Both heart rate variability and baroreflex sensitivity show wide variation in a normal population both within and between subjects. ${ }^{17}$ We have analysed very short segments of data to minimise the contribution of influences affecting heart rate variability, such as concentrations of hormones that act over longer time periods. We used metronomic respiration to standardise the response, and used a relatively low frequency $(0 \cdot 167 \mathrm{~Hz})$ because we observed that higher frequencies caused significant changes in resting heart rate during the procedure, possibly related to falling arterial carbon dioxide tension.

\section{HEART RATE VARIABILITY AFTER CARDIAC TRANSPLANTATION}

Heart rate variability is not determined only by the integrity of cardiac efferent nerves but also by the sensitivity and gain of central reflexes, and the integrity and responsiveness of afferent cardiac and sino-aortic sensory nerves. Only a very small proportion of variability persists immediately after transplantation and can be ascribed to the direct effects of stretch on the sinus node, or to persistent intracardiac ganglia. ${ }^{4}$ Bernardi et al ${ }^{14}$ studied the effects of neck suction on LF power in 26 subjects at 21 (SD 4) months after transplantation, and were able to increase LF power with suction at $0.1 \mathrm{~Hz}$ in about half of their subjects. They also found a relation between time after transplantation and the increase in LF power. This increase was blocked in four subjects after injection of esmolol suggesting sympathetic reinnervation. However, other factors may also play a part. Their method, using neck suction, involves the baroreceptors, and baroreflex sensitivity is reduced in subjects with heart failure.$^{18}$ Cardiac transplant recipients are survivors of cardiac failure, and although the reduced baroreflex sensitivity may recover with time, it does not do so completely. ${ }^{19}$

Other groups have also demonstrated increases in LF power but have not related these to direct measures of reinnervation. ${ }^{5615}$ We have shown that the LF part of the spectrum relates to a more direct measure of the degree of reinnervation, albeit a somewhat weak relation over the population as a whole.

\section{REINNERVATION}

Until recently, the occurrence of reinnervation was controversial. ${ }^{20}$ Sympathetic reinnervation has since been demonstrated using a number of different methods including anatomical, imaging, and functional techniques. Regrowth of nerves across the aortic anastomosis has been demonstrated using microscopy of autopsy specimens. ${ }^{21}$ In humans, a variety of imaging techniques have been used, including metaiodobenzylguanidine scintigraphy ${ }^{22}$ and positron emission tomography. ${ }^{23}$ Kaye et $a l^{24}$ demonstrated increased resting cardiac noradrenaline release late after transplantation and concluded that sympathetic reinnervation takes place and is incomplete. $\mathrm{We}^{7}$ and others ${ }^{8}{ }^{9}$ have already demonstrated that intracoronary injection of tyramine causes an increase in heart rate of more than five beats per minute in up to two thirds of subjects long term after cardiac transplantation. Heart rate changes have been related to noradrenaline spillover during sustained handgrip, suggesting that the change in heart rate may be used to estimate the amount of noradrenaline released, although this does not take into account differences in receptor sensitivity. ${ }^{25}$ The fact that response to tyramine relates to peak heart rate response during exercise in cardiac transplant recipients ${ }^{7}$ suggests that the response to tyramine is a measure of the capacity of cardiac nerves to influence heart rate.

A number of approaches have been used to detect potential parasympathetic reinnervation..$^{9}{ }^{26}$ Fitzpatrick et al ${ }^{26}$ studied the response to head up tilt, and inferred that parasympathetic reinnervation had occurred from heart rate changes at the time of head up tilt induced syncope and during a valsalva manoeuvre. These responses may however be explained by sympathetic reinnervation and withdrawal of sympathetic tone. ${ }^{1027}$ Arrowood et al ${ }^{11}$ concluded that vagal afferent reinnervation did not take place on the basis of the response to intracoronary contrast.

HEART RATE VARIABILITY AND REINNERVATION AFTER TRANSPLANTATION

The heart rate increases observed in our subjects after intracoronary injection of tyramine 

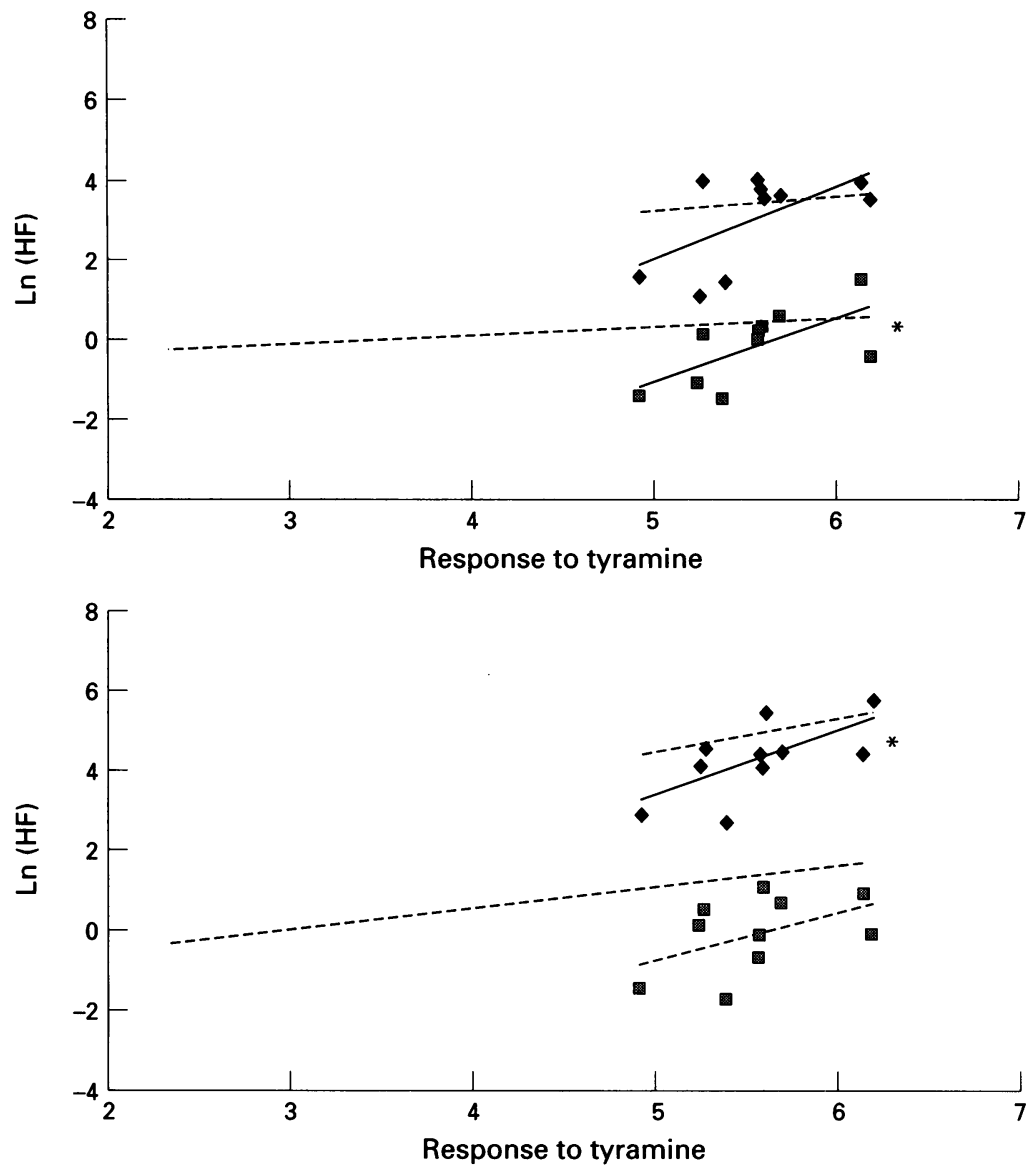

Figure 5 Relation between response to tyramine and the high frequency (HF) content of the spectrum in control subjects recorded at rest (upper panel) and during metronomic respiration (lower panel). Data from transplant recipients after atropine are not presented. Data from control subjects before atropine are shown as diamonds, and from control subjects after atropine as closed squares. Relations from the first experiment are reproduced as dashed lines for comparison. ${ }^{\star}$ Correlations statistically significant $(P<0 \cdot 05)$.

are the most direct measures of sympathetic reinnervation to the sinus node available, although we have not measured $\beta$ receptor sensitivity at the sinus node and may therefore assume that some of the variation in the degree of response is due to this. The slope of the relation between heart rate variability and response to tyramine is similar in controls and in transplant recipients, suggesting that changes in sympathetic effector mechanisms, either via sympathetic denervation or changing receptor sensitivity, affect heart rate variability in similar ways.

Table 3 Natural logarithm of low and high frequency content of the spectrum in transplant recipients and controls before and after atropine

\begin{tabular}{|c|c|c|c|c|}
\hline & \multicolumn{2}{|l|}{ High frequency } & \multicolumn{2}{|l|}{ Low frequency } \\
\hline & $\begin{array}{l}\text { Transplant } \\
\text { recipients } \\
(n=9)\end{array}$ & $\begin{array}{l}\text { Controls } \\
(n=10)\end{array}$ & $\begin{array}{l}\text { Transplant } \\
\text { recipients } \\
(n=9)\end{array}$ & $\begin{array}{l}\text { Controls } \\
(n=10)\end{array}$ \\
\hline $\begin{array}{l}\text { Rest } \\
\text { Before atropine } \\
\text { After atropine }\end{array}$ & $\begin{array}{l}-0.18(0.81) \\
-0.20(0.86)\end{array}$ & $\begin{array}{r}3.01(1.08)^{\star} \\
-0.22(0.93)\end{array}$ & $\begin{array}{l}-0.62(1.12) \\
-1.21(0.93)\end{array}$ & $\begin{array}{l}3.75(0.93)^{\star} \\
0.11(1.05)\end{array}$ \\
\hline $\begin{array}{l}\text { Metronomic respiration } \\
\text { Before atropine } \\
\text { After atropine }\end{array}$ & $\begin{array}{l}0.68(1.55) \\
0.96(1.69)\end{array}$ & $\begin{array}{r}4.37(0.87)^{\star} \\
-0.02(0.95)\end{array}$ & $\begin{array}{l}-0.93(1.07) \\
-0.85(1.34)\end{array}$ & $\begin{array}{r}3.23(0.54)^{\star} \\
-1.51(1.08)\end{array}$ \\
\hline
\end{tabular}

Values are expressed as mean (SD)

$\star$ Significant differences before and after atropine, $P<0.001$. Difference between transplan recipients and controls and between subjects at rest and during metronomic respiration are not shown.
HEART RATE VARIABILITY AND RESPONSE TO

TYRAMINE IN CONTROL SUBJECTS

Our control population cannot be assumed to have normal cardiac innervation and indeed showed evidence of a range of responsiveness to tyramine consistent either with partial cardiac denervation or reduced receptor sensitivity in some subjects. The difference in total spectral content between control subjects and transplant recipients may be explained either by normal parasympathetic innervation or by much increased sino-aortic baroreflex sensitivity in the control subjects. We studied a small number of control subjects, and found variation in all measurements of heart rate variability to be high, consistent with the observations of others. ${ }^{17}$

\section{LIMITATIONS}

Recommendations for standards of measurement of heart rate variability have recently been published. ${ }^{17}$ As we designed and performed our study before their publication, we were unable to use them. However, the methods used in our study do not differ very much from those recommended.

Heart rate variability after atropine was measured in control subjects both at the time of angiography and at a variable interval later, while transplant recipients were studied only on the day of their angiogram. As discussed earlier, the poor reproducibility of measures of heart rate variability means that the relations between response to tyramine and heart rate variability among controls must be interpreted with caution. Because the experiments were performed at the time of angiography, and intracoronary injection of tyramine depletes presynaptic stores of noradrenaline for some time, we were unable to assess the reproducibility of the response to tyramine.

The respiratory frequency we chose was relatively close to the (arbitrary) division between the LF and HF bands, and thus some of the variation caused by respiration may have leaked into the LF band. In order to exclude a significant contribution from this effect we reanalysed the metronomic respiration data using a single long sequence of $R R$ intervals allowing accurate localisation of the $\mathrm{HF}$ peak, albeit with increased variance. As we had hypothesised the relations between LF power and response to tyramine remained the same despite reduced leakage of the $\mathrm{HF}$ peak into the LF region, suggesting that its contribution is not important.

\section{CONCLUSIONS}

This is the first direct demonstration that increased heart rate variability is related to cardiac sympathetic reinnervation after cardiac transplantation. We have found no evidence for cardiac parasympathetic reinnervation. Further studies are required incorporating measurements of reflex sensitivity, receptor sensitivity, and using autonomic blockade both in transplant recipients and in suitable controls.

This study was partially supported by a grant from the British Heart Foundation grant no. BHF 95/173. RHC was supported by a BHF Intermediate Fellowship, FS95001. 
1 Pomeranz B, Macaulay RJB, Caudill MA, Kutz I, Adam D, Gordon D, et al. Assessment of autonomic function in humans by heart rate spectral analysis. Am $\mathcal{F}$ Physiol 1985;248:H151-3

2 Malliani A, Lombardi F, Pagani M. Power spectrum analysis of heart rate variability: a tool to explore neural regulatory mechanisms. Br Heart f 1994;71:1-2.

3 Saul JP, Arai Y, Berger RD, Lilly LS, Colucci WS, Cohen RJ. Assessment of autonomic regulation in chronic congestive heart failure by heart rate spectral analysis. $A m \mathcal{F}$ Cardiol 1988;61:1292-9.

4 Bernardi L, Keller F, Sanders M, Reddy PS, Griffith B, Meno $\mathrm{F}$, et al. Respiratory sinus arrhythmia in the denervated heart. $\mathcal{F}$ Appl Physiol 1989;67:1447-55.

5 Halpert I, Goldberg D, Levine AB, Levine TB, Kornberg $R$, Kelly $C$, Lesch $M$. Reinnervation of the human heart as evidenced from heart rate variability studies. $A m \mathcal{J}$ Cardiol 1996;77:180-3.

6 Smith ML, Ellenbogen KA, Eckberg DL, Sheehan HM, Thames MD. Subnormal parasympathetic activity afte cardiac transplantation $A m \mathcal{F}$

7 Lord SW, Brady S, Holt ND, Mitchell L, Dark JH, McComb JM. Exercise response after cardiac transplantation: relationship to reinnervation status. Heart 1996; 75:43-5.

8 Wilson RF, Christensen BV, Olivari MT, Simon A, White $\mathrm{CW}$, Laxson DD. Evidence for structural sympathetic reinnervation after orthotopic cardiac transplantation in humans. Circulation 1991;83:1210-20.

9 Wilson RF, Laxson DD, Christensen BV, McGinn AL, Kubo SH. Regional differences in sympathetic reinnervation after human orthotopic cardiac transplantation. Circulation 1993;88:165-71.

10 Morgan-Hughes NJ, Dark JH, Kenny RA, McComb JM. Vasovagal reactions after cardiac transplantation: relationship to reinnervation status. Clin Auton Res 1994;4: 125-9.

11 Arrowood JA, Goudreau E, Minisi AJ, Davis AB, Mohanty PK. Evidence against reinnervation of cardiac vagal afferents after human orthotopic cardiac transplantation. Circulation 1995;92:402-8.

12 Berger RD, Akselrod S, Gordon D, Cohen RJ. An efficient algorithm for spectral analysis of heart rate variability. IEEE transactions on biomedical engineering 1986;BME33: $900-4$.

13 Pagani M, Lombardi F, Guzzetti S, Rimoldi O, Furlan R Pizzinelli $P$, et al. Power spectral analysis of heart rate and arterial pressure variabilities as a marker of sympathovagal interaction in man and conscious dog. Circ Res 1986; 59:178-93.

14 Bernardi L, Bianchini B, Spadacini G, Leuzzi S, Valle F, Marchesi E, et al. Demonstrable cardiac reinnervation after human heart transplantation by carotid baroreflex modulation of RR interval. Circulation 1996;92: 2895-903.

15 Fallen EL, Kamath MV, Ghista DN, Fitchett D. Spectral analysis of heart rate variability following human heart transplantation: evidence for functional reinnervation. $\mathcal{F}$ Auton Nerv Syst 1988;23:199-206.

16 Sleight P, La Rovere MT, Mortara A, Pinna G, Maestri R, Leuzzi S, et al. Physiology and pathophysiology of heart rate and blood pressure variability in humans: is power spectral analysis largely an index of baroreflex gain? Clin Sci 1995;88:103-9.

17 Malik M (on behalf of the Task Force of the European Society of Cardiology and the North American Society of Pacing and Electrophysiology). Heart rate variability. Standards of measurement, physiological interpretation and clinical use. Circulation 1996;93:1043-65.

18 Creager MA, Creager SJ. Arterial baroreflex regulation of blood pressure in patients with congestive heart failure. $\mathcal{f}$ Am Coll Cardiol 1994;23:401-5.

19 Mohanty PK, Thames MD, Arrowood JA, Sowers MD, McNamara C, Szentpetery S. Impairment of cardiopulmonary baroreflex after cardiac transplantation in humans. Circulation 1987;75:914-21.

20 Bristow MR. The surgically denervated transplanted human heart. Circulation 1990;82:658-60.

21 Norvell JE, Lower RR. Degeneration and reinnervation of the nerves of the heart after transplantation. Transplantation 1973;15:337-44.

22 McComb JM, Hawkins T, Parry G, Dark JH. Scintigraphic assessment of reinnervation of the transplanted human heart [abstract]. Br Heart $\mathcal{F}$ 1994;71(Suppl):P109.

23 Schwaiger M, Hutchins GD, Kalff V, Rosenspire K, Hahka MS, Mallette S, et al. Evidence for regional catecholamine uptake and storage sites in the transplanted human heart by positron emission tomography. $f$ Clin Invest 1991;87:1681-90.

24 Kaye DB, Esler M, Kingwell B, McPherson G, Esmore D, Jennings $G$. Functional and neurochemical evidence for partial cardiac sympathetic reinnervation after cardiac partial cardiac sympathetic reinnervation after cardiac
transplantation in humans. Circulation 1993;88:1110-18.

25 Kingwell BA, Thompson JM, Kaye DM, McPherson GA, Jennings GL, Esler MD. Heart rate spectral analysis, cardiac norepinephrine spillover and muscle sympathetic nerve activity during human sympathetic nervous activation and failure. Circulation 1994;90:234-40

26 Fitzpatrick AP, Banner N, Cheng A, Yacoub M, Sutton R. Vasovagal reactions may occur after orthotopic hear transplantation. $\mathcal{F}$ Am Coll Cardiol 1993;21:1132-7.

27 Morgan Hughes NJ, Dark JH, McComb JM, Kenny RA Vasodepressor reactions may occur after cardiac transplantation [letter]. $\mathcal{F}$ Am Coll Cardiol 1993;22:2059. 